\title{
Pre-cooking of edible marine brown algae for reduction of arsenic contents
}

\author{
Masayuki Katayama $^{1}$, Yohko Sugawa-Katayama ${ }^{1}$, Kaori Murakami \\ ${ }^{1}$ Department of Health and Nutrition, Osaka Aoyama University, Mino-o, Osaka 562-8580, Japan \\ ${ }^{2}$ Department of Food Sciences and Biotechnology, Hiroshima Institute of Technology, Hiroshima 731-5193, Japan
}

Email address:

katayama@osaka-aoyama.ac.jp (Y. Sugawa-Katayama)

\section{To cite this article:}

Masayuki Katayama, Yohko Sugawa-Katayama, Kaori Murakami. Pre-Cooking of Edible Marine Brown Algae for Reduction of Arsenic Contents. Journal of Food and Nutrition Sciences. Special Issue: Food Processing and Food Quality. Vol. 3, No. 1-2, 2015 , pp. 84-87. doi: $10.11648 /$ j.jfns.s.2015030102.26

\begin{abstract}
Marine brown-algae are important edible seaweed in Japanese diets, because they are rich in nutritionally beneficial elements and dietary fiber as well for their umami-taste. In contrast to these benefits, they accumulate arsenic during their growth To overcome this inconvenience, some appropriate pre-cooking processes are desired to reduce arsenic contents. Quantitative determinations of arsenic contents after such processes with important species of marine brown algae, Hijiki (Sargassum fusiforme) and Akamoku (Sargassum horneri), are described here. Commercially available dried Hijiki was soaked in $4 \%$ acetic acid or $4 \%$ sodium hydrogen carbonate solution for certain periods of time and then the soaking solution was separated. Commercially available Akamoku was passed through boiling sodium chloride solution for short periods of time. After these processes, arsenic contents in Hijiki were found to be successfully reduced, as found with pure-water soaking. Loss of beneficial elements, iron, calcium, zinc and magnesium were described in the previous report ${ }^{1,2)}$. Arsenic contents in Akamoku are reduced in a shorter time than with Hijiki. The elution pattern of arsenic from Akamoku suggests that arsenic in Akamoku may exist in a loosely bound state than in Hijiki tissues.
\end{abstract}

Keywords: Hijiki, Sargassum fusiforme, Akamoku, Sargassum horneri, Arsenic-Diminishment, Water-Soaking, Acetic-Acid Soaking, Sodium-Hydrogen-Carbonate Soaking, Sodium-Chloride Solution

\section{Introduction}

Marine brown-algae accumulate higher levels of arsenic than other classes ${ }^{3)}$ of seaweeds. For example ${ }^{3)}$, Arame (Eisenia) contains $28 \mu \mathrm{g}$ As/g dry weight, Konbu (Luminaria), 30 95 $\mu \mathrm{g}$ As/g dry weigh, Wakame (Undaria), 34 110 $\mu \mathrm{g}$ As/g dry weight, and Hijiki (Sargassum) $110 \mu \mathrm{g}$ As/g dry weight. Out of them, Hijiki contains much ratio of inorganic arsenic compound $^{4,5)}$.

However, many members of this class have been utilized in Japanese dishes for long time. Most of them have delicious tastes as well as they are rich in nutritionally beneficial elements and dietary fiber.

Thus, it is necessary to have a means to remove arsenic as a pre-cooking process. In the previous report, the results of arsenic removal from the dried Hijiki after water-soaking at various temperatures ${ }^{5-7)}$, and effects on the contents of arsenic after treatment with artificial digestive enzymes ${ }^{8}$ ) were reported. On the other hand, Akamoku (Sargassum horneri) is a brown algae, recently used as an unique foodstuff ${ }^{9}$. Akamoku grew widely along Asian coast, so it is easy to harvest.

Although Akamoku is less popular than Hijiki as foodstuff, and it accumulates greater amounts of $\operatorname{arsenic}^{10)}$ than Hijiki ${ }^{11)}$, but the arsenic contents in Akamoku could be effectively reduced by parboiling in a sodium chloride solution ${ }^{12)}$. In comparison with Hijiki, differences in the existing state of arsenic in Akamoku may vary.

In this report, effects of acetic acid and sodium hydrogen carbonate solutions on the arsenic diminution in dried Hijiki and effects of temperature on the arsenic-content reduction in Akamoku are described.

\section{Methods}

\subsection{Plant Materials}

Hijiki plants: Hijiki, Sargassum fusiforme, grows on rocks on the sea-coast of Japan, bathed by the Kuroshio Current 
stream. The embryos of Hijiki are fixed on rocks and germinate in summer. In early winter, they grow to the primary-leaf stage through the germlings in autumn. Thereafter, Hijiki grows to become adult plants ${ }^{13-15)}$. Hijiki was harvested at seashores of Tsushima Archipelago, Japan, and processed for preparation of commercial products as dried Hijiki. Dried Hijiki samples were stored under $4^{\circ} \mathrm{C}$ until use. Akamoku plants: Akamoku, Sargassum horneri, grows in large areas along the coasts of Japan. Akamoku grows at an ocean depth of several $\mathrm{m}$ from winter to summer. After maturation, it drifts away from their growing sites. Fresh Akamoku plants were harvested in Yamada Bay, Iwate Prefecture, and stored under $-30^{\circ} \mathrm{C}$ until the experiment.

\subsection{Sample Treatments}

Hijiki: The dried Hijiki sample contained 89.1 $\pm 6.4 \mu \mathrm{g}$ As/g dried matter. The samples were cut into pieces of $0.5 \mathrm{~cm}$ to 1 $\mathrm{cm}$ in length and soaked in a $4 \%$ acetic acid solution or a $4 \%$ sodium hydrogen carbonate solution at various temperatures for a period of time as indicated. One gram each of the samples was mixed with 30 volumes of the solutions. The mixtures were separated through a filter under a reduced pressure. The residues were lyophilized and the solutions were spotted on a piece of filter paper, dried, and the whole was subjected to the radioactivation analysis for the determination of arsenic.

Akamoku: Ten grams each of wet samples was mixed with $50 \mathrm{ml}$ of the solutions for $5 \mathrm{~min}$. The mixtures were centrifugally separated at 3,500 rpm for $5 \mathrm{~min}$. The samples were stored under $-30^{\circ} \mathrm{C}$. The arsenic contents in the extracts were determined by HPLC-ICP MS spectrophotometer.

\subsection{Arsenic Determination}

i) Neutron activation analysis ${ }^{16,17)}$ : The dried samples or the water-soluble fractions spotted on a piece of filter paper were set in the center position of a research reactor of Kyoto Research Reactor Institute, Kyoto University. The thermal neutrons were irradiated at $10^{13}$ neutrons $\cdot \mathrm{cm}^{-2} \cdot \mathrm{sec}^{-1}$ for 20 min. After the cooling time of $72 \mathrm{hr}$, the arsenic content in the samples was determined by gamma-radiation from ${ }^{76}$ As using a pure Ge gamma-detector at $559.1 \mathrm{keV}$. The energy levels of ${ }^{60} \mathrm{Co}$ and ${ }^{137} \mathrm{Cs}$ were used for calibration.

ii) HPLC-ICP MS spectrophotometer: High performance liquid chromatography (HPLC) - Inductively Coupled Plasma - Mass (ICP-MS) spectrophotometry was performed in a $\mathrm{HNO}_{3}$ solution of liquid samples to determine the arsenic contents of the samples.

\subsection{Reagents}

Reagents were Special Grade Reagents of JIS or equivalent grades.

\section{Results and Discussion}

Hijiki: The effects of water-soaking on arsenic reduction in dried Hijiki were reported in the previous paper ${ }^{5-7)}$. By the water soaking, more than $70 \%$ of the total arsenic compounds were eluted. Out of the eluted arsenic, 60\% was inorganic arsenic, arsenate, and another was an organic arsenic compound. Their elution pattern suggested the inorganic arsenic compound existed in different state from the organic compounds in the tissues of the dried Hijiki samples. By a scanning electron microscopic observation, the freeze-fractured samples of Hijiki tissues showed dramatic changes during the water-soaking ${ }^{18)}$. These suggested the different distribution of the inorganic arsenic compounds from the organic arsenic compounds in the tissues.

The effect of $\mathrm{pH}$ in the soaking solution is interesting, as the existing state of arsenic is obscure, yet. Moreover, in consideration of regular home kitchens, acetic acid (4\%) and sodium hydrogen carbonate (4\%) were used for preparation of the soaking-solution. As the result, the dried Hijiki samples soaked in $4 \%$ acetic acid solution for $60 \mathrm{~min}$ at $60^{\circ} \mathrm{C}$ released $79 \%$ of the arsenic originally present in the tissues and at $90^{\circ} \mathrm{C}$, $85 \%$ of the total ${ }^{18)}$ (Fig 1).

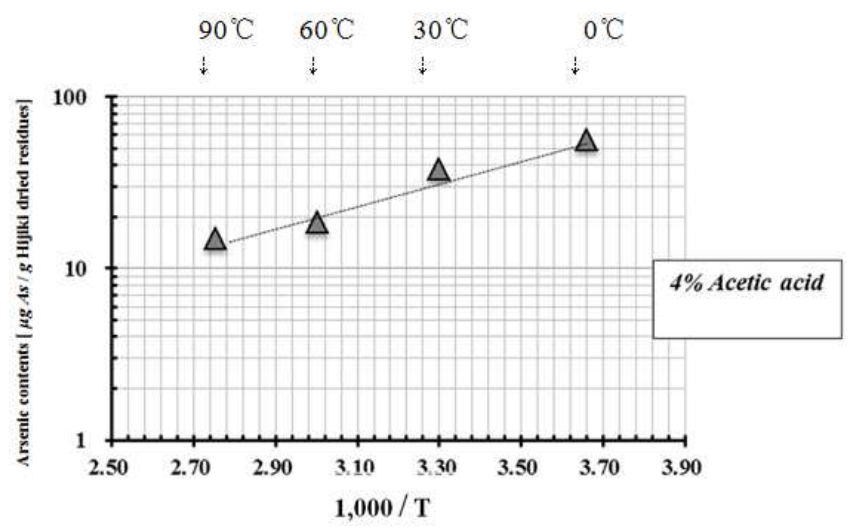

Fig 1. Effects of temperature on the reduction of arsenic contents in the dried Hijiki residues by soaking in $4 \%$ acetic acid solution ${ }^{18)}$.

Hijiki samples of $1 \mathrm{~g}$ were soaked in $30 \mathrm{ml}$ of $4 \%$ acetic acid solution at various temperatures and separated by filter under reduced pressure. The residues were lyophilized and a portion was determined for arsenic determination by neutron activation analysis. The ordinate expresses retained arsenic contents in the residues after the soaking, $\mu \mathrm{g}$ As/g dried matter of Hijiki samples. The axis of abscissa expresses 1,000/T. T expresses the absolute temperature $\left({ }^{\circ} \mathrm{K}\right)$. The experimental conditions were as described in the text.

In contrast to the pure-water soaking, the elution pattern by acetic-acid acidity seemed to be simpler. This may suggest that the acidic condition had changed the barrier of Hijiki tissues in the releasing of arsenic compounds.

Under the same conditions, the samples soaked in $4 \%$ sodium hydrogen carbonate solution released also at $60^{\circ} \mathrm{C}$, $77 \%$ of the total arsenic and at $90^{\circ} \mathrm{C}, 78 \%$ of the total 18$)(\mathrm{Fig}$ 2).

In alkaline solution brought by sodium hydrogen carbonate, the barriers in the cell walls of Hijiki tissues seemed to be weakened, too. Thus, the inflexion point was not clear in reciprocal curves as the Fig. 2. More investigation on these points should be done, as next problem. 


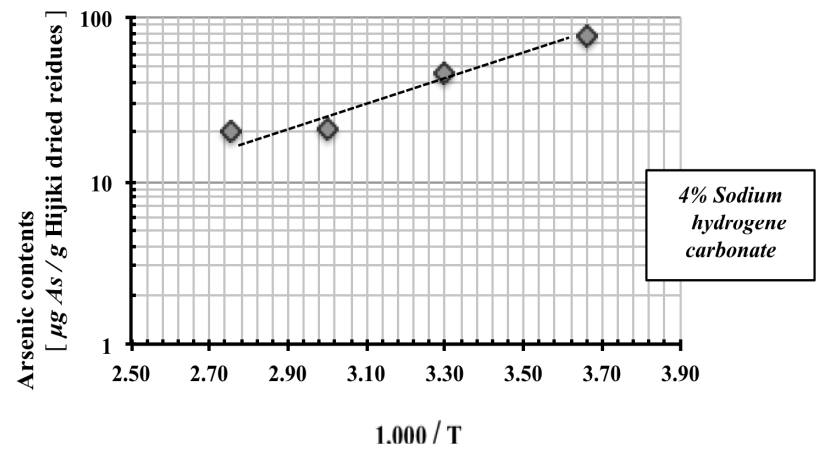

Fig 2. Effects of temperature on the reduction of arsenic contents in the dried Hijiki residues by soaking in $4 \%$ sodium hydrogen carbonate solution ${ }^{18}$.

Hijiki samples of $1 \mathrm{~g}$ were soaked in $30 \mathrm{ml}$ of $4 \%$ sodium hydrogen carbonate solution by conditions as described in Fig 1 and in the text.

During these procedures, some other elements were also released1). The loss of nutritionally important minerals, iron $(\mathrm{Fe})$, calcium $(\mathrm{Ca})$, zinc $(\mathrm{Zn})$ and magnesium $(\mathrm{Mg})$ were $32 \%$, $49 \%, 70 \%$ and $77 \%$, respectively, of the original contents in dried Hijiki samples, at $30^{\circ} \mathrm{C}$ during 30 min of water-soaking. Akamoku: Growing Akamoku accumulates twice concentrations of $\operatorname{arsenic}^{10)}$ in comparison with Hijiki plants ${ }^{11)}$ growing at the same sea-coast area where Akamoku was harvested. Thus, the arsenic reduction is essential in the pre-cooking procedure. By parboiling the Akamoku in sodium chloride solution, $90 \%$ of arsenic was removed ${ }^{12)}$ by changing the immersing water three times. To know the detail of the arsenic-elution process, the arsenic release was measured by changing the elution temperature ${ }^{19)}$ (Fig 3).

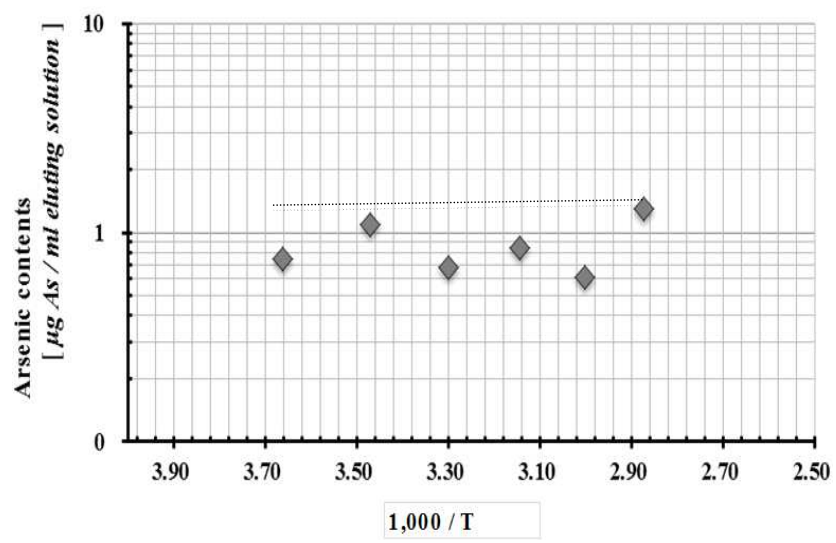

Fig 3. Effects of temperature on the elution of arsenic from Akamoku tissues into solution ${ }^{19)}$.

Akamoku samples of $10 \mathrm{~g}$ were mixed in $50 \mathrm{ml}$ of water at various temperature for $5 \mathrm{~min}$ and separated centrifugally under $0^{\circ} \mathrm{C}$. The arsenic concentration in the solution was determined as acidic solution in $\mathrm{HNO} 3$ by HPLC- ICP-MS spectrophotometry and expressed in $\mu \mathrm{g} \mathrm{As} / \mathrm{ml}$ eluting solution. $\mathrm{T}$ on the axis of abscissas expresses absolute temperature $\left({ }^{\circ} \mathrm{K}\right)$.

These curves showed that the arsenic release occurred more easily in Akamoku than in the case of Hijiki, suggesting a more releasable form of arsenic exists in Akamoku than in Hijiki.

In general, each member of the brown-algae class should be studied for their existing organic state of arsenic as well as inorganic state of arsenic with their accumulating minerals, in order to utilize these algae more sensibly.

\section{Acknowledgement}

The authors express their appreciation to the Tsushima Archipelago-Third Sectional Hijiki Processing Company, Nagasaki Pref., for their generous gifts of Hijiki commercial products, and to Prof. Kita, K., Iwate University, Morioka, Iwate Pref., for their generous gifts of Akamoku.

Also, the authors express their appreciation to Mr. Nakano Y., Research Reactor Institute, Kyoto University, for his technical support in the arsenic determination by neutron activation analysis.

\section{References}

[1] Sugawa-Katayama, Y. and Katayama, M. (2007) Release of minerals from dried Hijiki, Sargassum fusiforme (Harvey) Setchell, during water-soaking. Trace Nutrients Research, 24: 106-109

[2] Katayama, M. and Sugawa-Katayama, Y. (2012) (Biological behaviors of minerals in Hijiki, Sargassum fusiforme. First AFSSA Conference Proceedings on Food Safety and Security, September 15-17. 2012, Osaka, Japan. Page: 88-91.

[3] Suzuki, Y. and Tanusi, S. (1993) $15^{\text {th }}$ Group- ALGAE. in Table of Trace Element Contents in Japanese Foodstuffs, ed. By Suzuki, Y. and Tanusi, S., (Dai-ichi Shuppan Pub. Co. Ltd, Tokyo), 150-156.

[4] Jin, K. (1983) Arsenic concentrations in sea algae produced in Hokkaido - Determination of total arsenic and differential determination of inorganic arsenite and arsenate, methylarsonate and dimethylarsinate. Hokkaido Eiken Syouhou (Rep. Hokkaido Inst. Publ. Health) 33: 21-27.

[5] Katayama, M., Sugawa-Katayama, Y., Yamaguchi, Y., Murakami, K. and Hirata, S. (2008) Effect of temperature on the extraction of various arsenic compounds from dried Hijiki, Sargassum fusiforme by water-soaking as a precooking process. Trace Nutrients Research, 25: 134-138.

[6] Sugawa-Katayama, Y., Katayama, M., Yamamoto, Y., Sawada, R. and Nakano, Y. (2005) Diminution of the arsenic level in Hijiki, Sargassum fusiforme (Harvey) Setchell through pre-cooking treatment. Trace Nutrients Research, 22: 107-109.

[7] Katayama, M. and Sugawa-Katayama, Y. (2007) Effect of temperature on the diminution of retained arsenic in the dried Hijiki, Sargassum fusiforme (Harvey) Setchell, by water-soaking. J. Home Econ. Jpn. 58: 75-80.

[8] Sugawa-Katayama, Y., Katayama, M., Imanishi, H. and Tomita, K. (2010) Effects of digestive enzymes on the retained arsenic in dried Hijiki, Sargassum fusiforme. Trace Nutrients Research, 27: 84-87.

[9] Murakami, K., Yamaguchi, Y., Noda, K., Fujii, T., Shinohara, N., Ushirokawa, T., Sugawa-Katayama Y., and Katayama, M. (2011) Seasonal variation in the chemical composition of a marine brown alga, Sargassum horneri (Turner) C. Agardh. J. Food Composition and Analysis, 24: 231-236. 
[10] Katayama, M., Sugawa-Katayama, Y., Sawada, R., and Yamamoto, Y. (2008) Distribution of accumulated arsenic in the plant body of Akamoku, Sargassum horneri. Trace Nutrients Research, 25: 129-133.

[11] Katayama, M., Yamamoto, Y., Sawada, R. and Sugawa-Katayama, Y. (2008) Distribution of accumulated arsenic in the seaweed Hijiki, Sargassum fusiforme (Harvey) Setchell. J. Osaka Aoyama University, 1: 29-34.

[12] Murakami, K. Sugawa-Katayama, Y. and Katayama, M. (2013) Effect of parboiling on and seasonal variations of the arsenic content in the marine brown alga, Sargassum horneri. IUNS $20^{\text {th }}$ International Congress of Nutrition, PO-3182.

[13] Suto, S. (1951) On shedding of eggs, liberation of embryos and their later fixing in Hijikia fusiforme. Nihon Suisan Gakkaishi, 17: 9-12.

[14] Suto, S. (1951) On growth of "Bush", in Hijikia fusiforme. Nihon Suisan Gakkaishi, 17: 12-14.

[15] Arai, S. (1993) Hijikia fusiformis. in An Illustrated Atlas of the
Life History of Algae. (Uchida Rokakuho Pub. Co. Ltd., Tokyo), 2: 166-167.

[16] Katayama, M., Sugawa-Katayama, Y., and Otsuki, K. (1994) Effects of Hijiki feeding on arsenic distribution in rats administered large doses of arsenate. Appl. Organometallic Chemistry, 8: 259-264.

[17] Sugawa-Katayama, Y., Katayama, M., Sakiyama, C., Nakano, Y. (2004) Distribution of accumulated arsenic in the seaweed Hijiki, Sargassum fusiforme (Harvey) Setchell -(2). Bull. Fac. Hum. Envirn. Sci., Fukuoka Women's Univ., 35: 81-90.

[18] Sugawa-Katayama, Y. and Katayama, M. (2014) Effects of acetic acid and sodium hydrogen carbonate on arsenic diminution in dried Hijiki, Sargassum fusiforme, during pre-cooking water-soaking. J Home Econ. Jpn., 65: 21-26.

[19] Katayama, M. Sugawa-Katayama, Y., Murakami, K. and Yamaguchi, Y. (2014) Effect of temperature on release of arsenic from brown alga Akamoku, Sargassum horneri. In preparation for contribution. 